\title{
Rules of Ozone Generation Induced by Yellow Phosphorus
}

\author{
Li Zhang, Yihong Qin, Chengxiao Nie, Baizhen Chen \\ School of Metallurgy and Environment \\ Central South University \\ Changsha,410083,China \\ e-mail: zlylcsu@163.com
}

\begin{abstract}
The rules of ozone generation produced by yellow phosphorus and oxygen were carried out by single-factor experiments in this article. The results showed that with fixed yellow phosphorus concentration $\left(2\right.$ g.L $\left.^{-1}\right)$ and oxygen volume percentage $(10 \%)$, the rate of ozone net generation

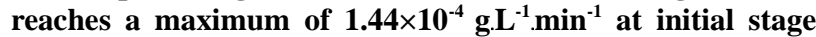
when reaction temperature, stirring speed, and flow rate reach $50{ }^{\circ} \mathrm{C}, 800 \mathrm{r} \cdot \mathrm{min}^{-1}$ and $600 \mathrm{~mL} \cdot \mathrm{min}^{-1}$ respectively. There is a clear linear relationship between the total concentration of ozone net generation and the initial concentration of yellow phosphorus, which is $:=1: 2$ in experimental conditions. The total concentration of ozone generation is reduced by increasing temperature or stirring speed, but increased by raising oxygen concentration. Adding limestone may lead to the decrease of both the rate and total quality of ozone production. The $\mathrm{pH}$ value of this reaction system can rapidly reach a stable state, which can be well utilized to the separation and recovery of phosphorus.
\end{abstract}

Keywords-yellow phosphorus; ozone; net generation rate; net generation concentration

\section{INTRODUCTION}

Ozone $\left(\mathrm{O}_{3}\right)$ is recognized as a powerful oxidizing agent, and its redox potential in water ranks second, only inferior to fluoride. As a highly reactive oxidant, disinfectant, refining agent and catalyst, ozone has been widely used in many industrial sectors, such as chemistry, petroleum, textile, food, spices, pharmaceuticals, and so on $[1,2]$. In recent years, ozone has also been widely applied to flue gas [3-8] and water treatment [9-12]. Generally, ozone is produced by electro-discharge, in which oxygen molecules split into oxygen atoms, and then into ozone molecules. The process is carried out in a specialized ozone generator and consumes lots of power [13-17]. Obviously, taking the reaction between yellow phosphorus and oxygen to produce ozone has easy condition with no need to add new equipment or upgrade existing crafts, and ozone can generate and react simultaneously to assure its effective utilization.

Phosphorus induced oxidation technology was first proposed by Berkeley National Laboratory in the United States in 1990, and tried to the oxidation process of NO to $\mathrm{NO}_{2}$ in wet desulfurization and denitrification of flue gas [18]. After that, this technology was applied to waste water treatment [19-21], which obtained good oxidation effects. The core of this technology is producing ozone by reactions between yellow phosphorus and oxygen. However, most researchers are focused on the effects of ozone oxidation, and few attentions have been paid on the rules of ozone generation. Considering that ozone is not stable both in gas and aqueous solutions and easy to break up, only its net generating concentration can be used in practice. Therefore, the study on the rules of ozone generation during the process of reacting yellow phosphorus with oxygen is conducive to improve the efficiency of ozone utilization and oxidation, and provides theoretical guidance for further development and application of ozone oxidation technology.

\section{EXPERIMENTAL}

The experimental setup used in the present work is shown in Figure 1. Oxygen of a certain concentration was obtained by distributing compressed oxygen of $99.8 \%$ and compressed nitrogen of $99.99 \%$ in a gas sample compounder of MF-4B, and then passed into yellow phosphorus emulsion to generate ozone. In a typical experiment, a gaseous mixture contained $10 \%$ of $\mathrm{O}_{2}$ went through the bottom of a three necked flask, in which $0.1 \mathrm{~g}$ of yellow phosphorus was dispersed in $0.5 \mathrm{~L}$ of deionized water by a magnetic stirring speed of 800 r.min ${ }^{1}$ to be emulsion. The gas flow rate was kept at 400 $\mathrm{mL} \cdot \mathrm{min}^{-1}$, and reaction temperature was maintained at 50 ${ }^{\circ} \mathrm{C}$. Ozone produced in the process was absorbed by indigo carmine solution and then measured by indigo carmine spectrophotometry [22].

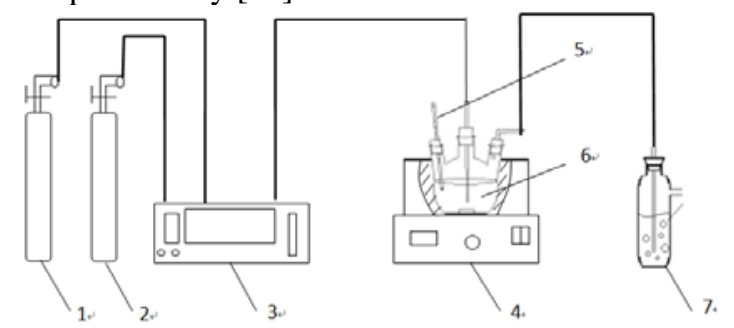

Figure 1. Schematic diagram of experimental setup 1.Oxygen cylinder 2.Nitrogen cylinder 3.Gas sample compounder 4.Water bath 5.Thermometer 6.Yellow phosphorus emulsion 7.Indigo carmine solution

\section{Results And Discussion}

\section{Effect of reaction temperature}

Yellow phosphorus is a yellow-white waxy solid at room temperature, insoluble in water. When the reaction temperature is lower than its melting point, namely $44.1^{\circ} \mathrm{C}$, yellow phosphorus is not easily broken even in strong agitation, and in poor contact with oxygen. When the reaction temperature is higher than the melting point, yellow phosphorus turns into molten state and disperses in water to form a water emulsion in the stirring. In this way, it can easily react with oxygen. However, when the reaction temperature is higher than $60^{\circ} \mathrm{C}$, yellow 
phosphorus begins to combust in solution. The effect of reaction temperature on ozone generation is depicted in Figure 2 changing experimental temperature from $45^{\circ} \mathrm{C}$ to $60^{\circ} \mathrm{C}$.

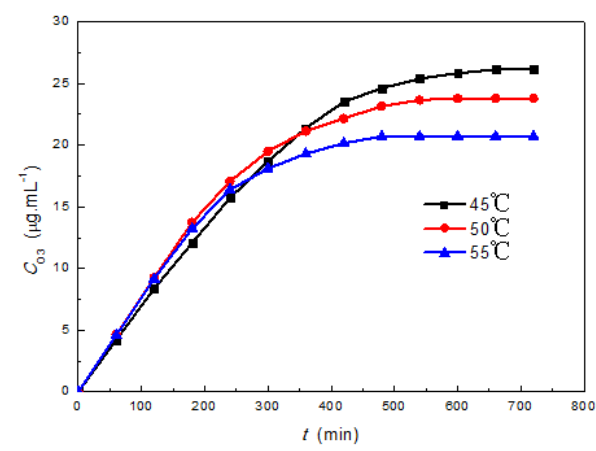

Figure 2.

Effect of reaction temperature on ozone net generation concentration

Figure 2 reveals that the rate of ozone net generation increases with temperature at the initial stage, and reaches a maximum of $7.72 \times 10^{-5} \mathrm{~g} . \mathrm{L}^{-1} \cdot \mathrm{min}^{-1}$ at $50^{\circ} \mathrm{C}$. Furthermore, the time needed for complete consumption of yellow phosphorus of the same quality is shorten and the total concentration of ozone net generation decreases with increasing temperature. It can be explained from the following two aspects: First, chemical reactions of ozone generation can be quicken by raising temperature. Second, ozone is not stable and its decomposition rate may be accelerated by increasing temperature. The combined action of the two aspects results in the change of ozone generation process. In practical application, ozone reacts with flue gas or waste water immediately once it generates, which suppresses the self-decomposition of ozone and greatly improves the utilization efficiency of ozone.

\section{Effect of stirring speed}

Mechanical stirring is the most common way to improve the contact condition of reactive substances. As shown in Figure 3, the rate of ozone net generation obviously increases when the stirring speed increases from $600 \mathrm{rmin}^{-1}$ to $800 \mathrm{rmin}^{-1}$. The main reason is that gas and yellow phosphorus emulsion can not be fully contacted with each other at the stirring speed lower than $800 \mathrm{rmin}{ }^{-1}$. Once the stirring speed is up to $800 \mathrm{rmin}^{-1}$, ozone net formation rate no longer increases, and the increase of ozone generation rate and ozone decomposition rate is substantially equal. Moreover, total concentration of ozone net generation decreases with the increase of stirring speed, which mainly result from ozone decomposition speeded-up under strong stirring.

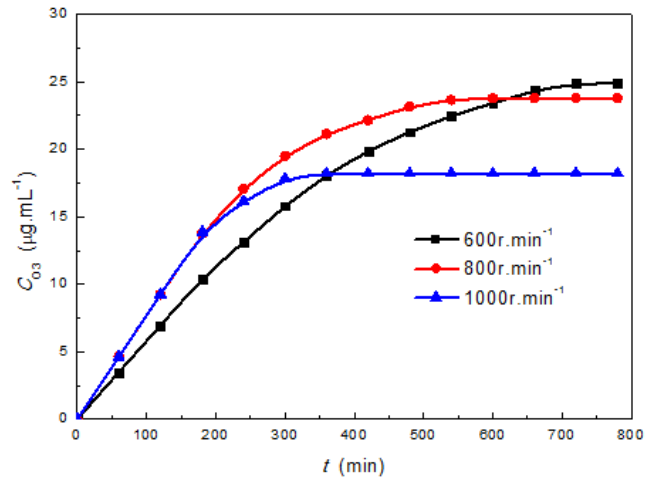

Figure 3. Effect of stirring speed on ozone net generation concentration

\section{Effect of yellow phosphorus initial concentration}

As one of the reactants, the initial concentration of yellow phosphorus directly affects the reaction. Concentration curve of ozone net generation as time in different initial concentration of yellow phosphorus is shown in Figure 4. It can be found that ozone net generation rate rises with the increase of the initial concentration of yellow phosphorus. It is mainly because increasing the concentration of reactant--which is yellow phosphorus--will be conducive to ozone generation reaction in the positive direction.

Obviously, enlarging the initial concentration of yellow phosphorus eventually results in increasing total concentration of ozone net generation. Figure 5 shows the change of total concentration of ozone net generation as different concentration of yellow phosphorus. After linear fitting, there is a good linear relationship between total concentration of ozone net generation and the initial concentration of yellow phosphorus, whose linear correlation(R) up to 0.9991. According to the fitted curve, it is easy to get its slope value (b) 0.0952, from which the mole ratio of yellow phosphorus consumption and ozone net production is calculated to 1:2. Based on this result, it is easy to determine the dosage of yellow phosphorus during the process of flue gas and wastewater treatment.

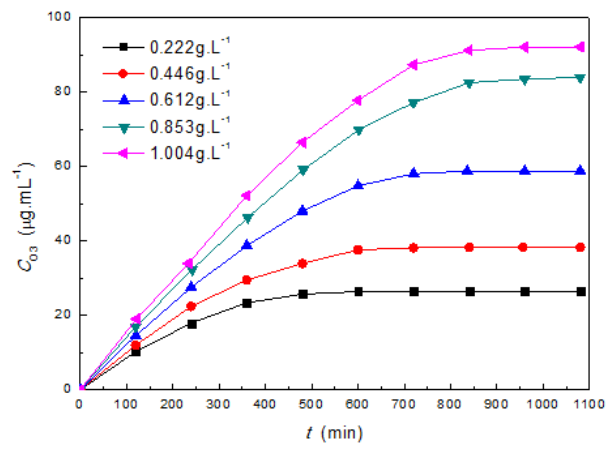

Figure 4.Effect of yellow phosphorus initial concentration on ozone net generation concentration 


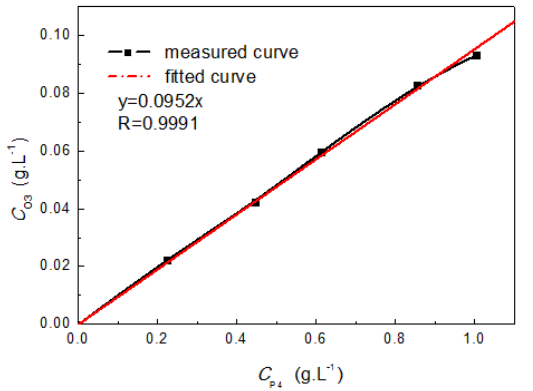

Figure 5.Total concentration of ozone net generation as a function of yellow phosphorus initial concentrition

\section{Effect of oxygen concentration}

As another reactant, oxygen concentration also directly affects the reaction. There are two ways in which oxygen concentration contact with yellow phosphorus emulsion in unit time can be changed. The first way is to change the volume percentage of oxygen concentration at fixed flow rate of mixed gas. The second way is to change the flow rate of mixed gas in fixed oxygen concentration. The rules of the rate and total concentration of ozone net generation as oxygen concentration were studied on flow rate of $400 \mathrm{mLmin}^{-1}$ (Figure 6) and oxygen volume concentration of $10 \%$ (Figure 7), respectively.

Comparing Figure 6 and Figure 7, it can be seen that the curves present substantially the same rules, ozone net generation rate increases at first and then remains in a maximum as the increase of oxygen concentration contacted with yellow phosphorus emulsion in unit time. In addition, the total concentration of ozone net generation increases gradually. It is mainly because that raising the concentration of reactant oxygen will lead ozone production reaction to positive direction, which improves the preparation of ozone. When ozone is up to a certain concentration, oxygen contact with yellow phosphorus emulsion is beyond what is required. Hence, further increasing its concentration has little effect on ozone production. Oxygen is the product of ozone decomposition, and raising its concentration will inhibit the decomposition of ozone, which results in the increase of ozone net production.

Usually, oxygen concentration in coal-fired flue gas is about $10 \%$. As a result, ozone net generation rate has a maximum of $1.44 \times 10^{-4} \mathrm{gLL}^{-1} \mathrm{~min}^{-1}$ at a flow rate of 600 $\mathrm{mL} \cdot \mathrm{min}^{-1}$ without adding extra air.

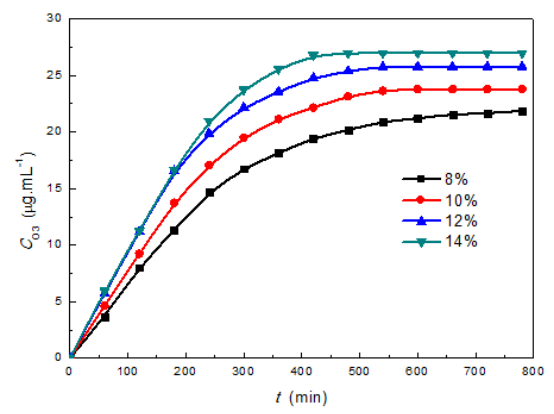

Figure 6.

Effect of oxygen volume concentration on ozone net generation concentration

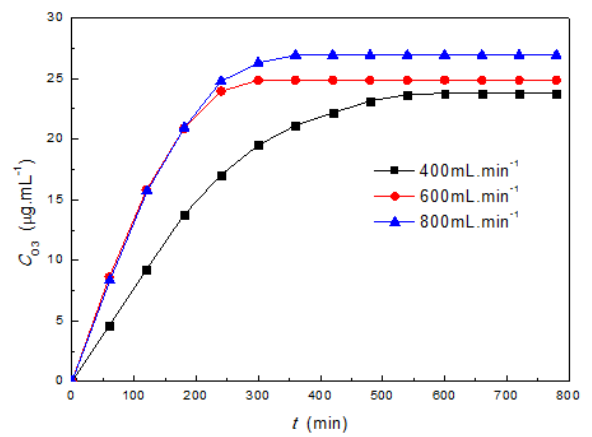

Figure 7. Effect of gas flow rate on ozone net generation concentration

\section{Effect of adding limestone}

Oxidization technology induced by yellow phosphorus is generally applied to exhaust smoke's treatment combined with wet desulfurization technology, and limestone is the most widely used adding agent. Thus, limestone was selected in the experiment, and there is a comparison of ozone net generation concentration and $\mathrm{pH}$ value on the condition of adding limestone or not (Figure 8 \& Figure 9). Figure 8 shows that both the rate and total quality of ozone net generation go down after adding limestone, accompanying the raise of $\mathrm{pH}$ value from about 3 to 5(Figure 9). Refer to literature [23], the decomposition of ozone may be promoted when $\mathrm{pH}$ value rising to 5. But adding limestone has little effect on ozone generation. Hence, adding limestone may lead to decrease the rate and total quality of ozone net generation.

However, the $\mathrm{pH}$ value reaches a platform quickly with adding limestone or not (Figure 9). It demonstrates that phosphoresced oxidation produced by the reaction of yellow phosphorus and oxygen only dissolves partly in reaction system at initial stage, and then enters into subsequent gathering system in the form of smoke. Hence, it is very easy to separate and recover phosphorus from this system in the form of phosphoric acid.

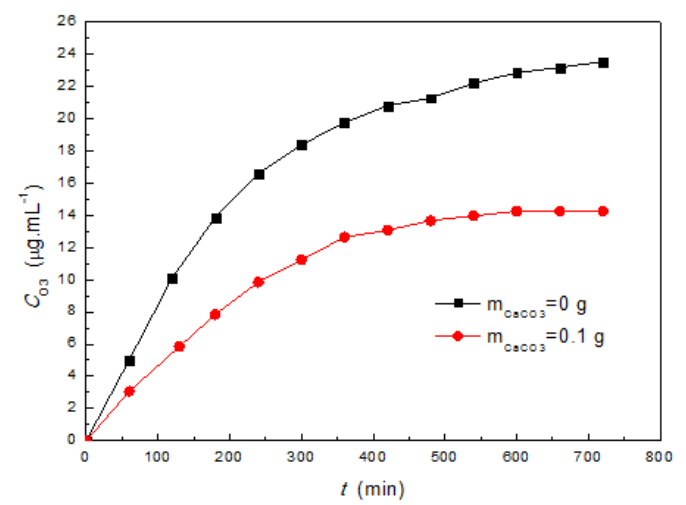

Figure 8.

Change of ozone generation concentration as time with limestone or not 


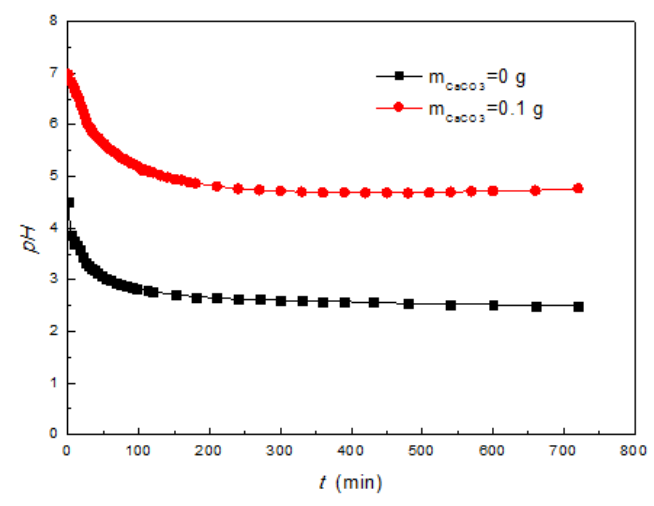

Figure 9.

Change of $\mathrm{pH}$ value as time with limestone or not

\section{CONCLUSIONS}

(1)Ozone net generation reaches a more desirable state when raising reaction temperature, stirring speed, yellow phosphorus concentration or oxygen concentration. With fixed concentration of yellow phosphorus $\left(2\right.$ g. $\left.\mathrm{L}^{-1}\right)$ and volume percent of oxygen (10\%), the rate of ozone net generation reaches a maximum of $1.44 \times 10^{-4}$ g. $L^{-1} \cdot \mathrm{min}^{-1}$ at initial stage on the condition that reaction temperature is $50{ }^{\circ} \mathrm{C}$, stirring speed is $800 \mathrm{rmmin}^{-1}$, and flow rate is 600 $\mathrm{mL} \cdot \mathrm{min}^{-1}$.

(2)Keeping other conditions in fixed values, there is a good linear relationship between total concentration of ozone net generation and initial concentration of yellow phosphorus--- :=1:2, which can be used as the calculation basis of the dosage of yellow phosphorus during the process of treating flue gas and waste water.

(3)The total concentration of ozone net generation may be reduced with the increase of reaction temperature or stirring speed, but increased by raising oxygen concentration, which has its inhibition to ozone selfdecomposition.

(4)Adding limestone may lead to the decrease of the rate and total quality of ozone production. The $\mathrm{pH}$ value of this reaction system can rapidly go to a stable state, which can be well utilized to the separation and recovery of phosphorus.

\section{ACKNOWLEDGMENT}

The research was financially supported by the Hunan Provincial Innovation Foundation for Postgraduate.

\section{REFERENCES}

H. Li and Y.Q. Yu, "Fundamental research and application process on ozone,” Guangzhou Chemical Industry, vol. 37, Oct. 2009, pp. 12-14, doi: 10.3969/j.issn.1001-9677.2009.07.004.

B.L. Loeb, “Ozone: thirty-three years and growing,” Ozone: Science \& Engineering, vol. 33, July. 2011, pp. 329-342, doi: 10.1080/01919512.2011.584302.

Z.H. Wang, J.H. Zhou, J.R. Fan, and C. Kefa, “ Direct numerical simulation of ozone injection technology for $\mathrm{NO}_{\mathrm{x}}$ control in flue gas," Energy Fuels, vol. 20, Oct. 2006, pp. 2432-2438, doi: 10.1021/ef0603176.

Z.H. Wang, J.H. Zhou, L.S. Wei, Z.C. Wen and K.F. Cen, “Experimental research for the simultaneous removal of $\mathrm{NO}_{\mathrm{x}}$ and $\mathrm{SO}_{2}$ in flue gas by $\mathrm{O}_{3}$," Proceedings of the Chinese Society for Electrical Engineering, vol. 27, Apr. 2007, pp.1-5, doi: 10.3321/j.issn:0258-8013.2007.11.001.
L.S. Wei, J. H. Zhou, Z.H. Wang and K.F. Cen, "Research on simultaneous desulfurization and denitrification by ozone oxidation integrated with chemical scrubber:theoretical analysis of $\mathrm{SO}_{\mathrm{x}}$ and $\mathrm{NO}_{\mathrm{x}}$ absorption properties of limestone slurry," Journal of Power Engineering, vol. 28, Feb. 2008, pp. 112-116, doi : 10.3321/j.issn:1000-6761.2008.01.025.

L.S. Wei, Z.J. Hu, Y.F. Zhang and Q.F. Wu, "Experimental study on ozone generation and ozone oxidation to removal multipollutant of flue gas," Bioinformatics and Biomedical Engineering (iCBBE 04), IEEE Press, June. 2010, doi: 10.1109/ICBBE.2010.5515999

W.Y. Sun, S.L. Ding, S.S. Zeng, S.J. Su and W.J. Jiang, “Simultaneous absorption of $\mathrm{NO}_{\mathrm{x}}$ and $\mathrm{SO}_{2}$ from flue gas with pyrolusite slurry combined with gas-phase oxidation of NO using ozone," Journal of Hazardous Materials, vol. 192, May. 2011, pp. 124-130, doi: 10.1016/j.jhazmat.2011.04.104.

Z.H. Wang, X. Zhang, Y. Q. Zhu, Z. Q. Ling, Z. J. Zhou and J. H. Zhou, "Development of catalyst-sorbents for simultaneous removal of $\mathrm{SO}_{2}$ from flue gas by low temperature ozone oxidation,” Ozone: Science and Engineering, vol. 34, May. 2012, pp. 204-212, doi: 10.1080/01919512.2012.663726.

K.Y. Park, S.K. Maeng, K.G. Song and K.H. Ahn, "Ozone treatment of wastewater sludge for reduction and stabilization,” Journal of Environmental Science and Health Part A, vol. 43, Dec. 2008, pp. 15461550, doi: 10.1080/10934520802293719.

S. Tripathi, V. Pathak, D.M. Tripathi and B.D. Tripathi, “Application of ozone based treatments of secondary effluents," Bioresource Technology, vol. 102, Feb. 2011, pp. 2481-2486, doi:10.1016/j.biortech.2010.11.028.

M. Ibáñez, E. Gracia-Lor, L. Bijlsma, E. Morales, L. Pastor and F. Hernández, "Removal of emerging contaminants in sewage water subjected to advanced oxidation with ozone,” Journal of Hazardous Materials, vol. 260, Sept. 2013, pp. 389-398, doi: 10.1016/j.jhazmat.2013.05.023.

M.S. Lucas, J.A. Peres and G.L. Puma, “Treatment of winery wastewater by ozone-based advanced oxidation processes $\left(\mathrm{O}_{3}, \mathrm{O}_{3} / \mathrm{UV}\right.$ and $\mathrm{O}_{3} / \mathrm{UV} / \mathrm{H}_{2} \mathrm{O}_{2}$ ) in a pilot-scale bubble column reactor and process economics," Separation and Purification Technology, vol. 72, May. 2010, pp. 235-241, doi: 10.1016/j.seppur.2010.01.016.

S.L. Park, J.D. Moon, S.H. Lee and S.Y. Shin, "Effective ozone generation utilizing a meshed-plate electrode in dielectric-barrier discharge type ozone generator,” Journal of Electrostatics, vol. 64, May. 2006, pp. 275-282, doi: 10.1016/j.elstat.2005.06.007.

Z. Fang, Y.C. Qiu, Y.Z. Sun, H. Wang and K. Edmund, "Experimental study on discharge characteristics and ozone generation of dielectric barrier discharge in a cylinder-cylinder reactor and a wire-cylinder reactor," Journal of Electrostatics, vol. 66, July. 2008, pp.421-426. doi:10.1016/j.elstat.2008.04.007.

T. Poznyak, I. Chairez, C. Perez, and A. Poznyak, "Switching robust control for ozone generators using the attractive ellipsoid method," ISA Transactions, vol. 53, Nov. 2014, pp.1796-1806, doi:10.1016/j.isatra.2014.08.011.

L.S. Wei, D.K. Yuan, Y.F. Zhang, Z.J. Hu and G.P. Dong, "Experimental and theoretical study of ozone generation in pulsed positive dielectric barrier discharge,” Vacuum, vol.104, June. 2014, pp.61-64, doi:10.1016/j.vacuum.2014.01.009.

S. Jodpimai, S. Boonduang and P. Limsuwan, "Dielectric barrier discharge ozone generator using aluminum granules electrodes," Journal of Electrostatics, vol. 74, Apr. 2015, pp.108-114, doi: doi:10.1016/j.elstat.2014.12.003.

S.G. Chang and D.K. Liu, "Removal of nitrogen and sulphur oxides from waste gas using a phosphorus/alkali emulsion,” Nature, vol. 343, Jan. 1990, pp. 151-154, doi: 10.1038/343151a0.

K.Y. Hu, Y.Z. Wang and S.G. Chang, "Oxidation of phenol in aqueous solution induced by reactions of yellow phosphorous with oxygen," Acta Scientiae Circumstantiae, vol. 15, Apr. 1995, pp. 199-207, doi:10.13671/j.hjkxxb.1995.02.011.(in Chinese)

H. Wang, Y. Shi, L. Le, S.M. Wang, J.L. Wei and S. G. Chang, "POZONE technology to bleach pulp," Industrial\&Engineering Chemistry Research, vol. 36, Sept. 1997, pp. 3656-3661, doi: 10.1021/ie960621u.

Y. Shi, F. Xiang, Z.C. Wu and S.Q. Zhang, "Study on POZONE/UV technology for organic wastewater treatment,” Environmental Pollution and Control, vol. 25, Apr. 2003, pp.1-4, doi: 10.3969/j.issn.10013865.2003.02.004(in Chinese) 
L.C. Jiang, S.M. Tang, Q. You, Y.H. Wang and J. Peng, "Spectrophotometric determination of ozone in water by the colorfading reaction of sodium indigo disulfonate," Physical Testing and Chemical Analysis(Part B:Chemical Analysis), vol. 47, 2011, pp. 180182. (in Chinese)
G.X. Tan, Y.P. Chen and X.P. Xu, "Ozone deceposition rules in gaseity and aqueous solution," Journal of Shanghai University(Natural Science Edition), vol. 11, 2005, pp. 510-512.(in Chinese) 